\title{
Non-Invasive Intracranial Pressure Evaluation in an Emergency Room - Point-of-Care Ultrasonography
}

\section{Avaliação não invasiva da pressão intracraniana em uma sala de emergência - ultrassonografia point-of-care}

\author{
Daniel Damiani $^{1}$ Durval Damiani ${ }^{2}$ \\ 1 Pós-Graduação em Neurociências, Universidade Anhembi Morumbi, \\ São Paulo, SP, Brazil \\ 2 Faculdade de Medicina, Universidade de São Paulo, São Paulo, SP, Brazil \\ Address for correspondence Daniel Damiani, MD, Universidade \\ Anhembi Morumbi, Rua Doutor Almeida Lima 1.134, Parque da \\ Mooca, São Paulo, SP, 03164-000, Brazil \\ Arq Bras Neurocir 2019;38:279-283. \\ (e-mail: dani.neurocirurgia@gmail.com).
}
Abstract
Keywords
- point-of-care ultrasound
- ultrasound in emergency room
- ultrasound in neurocritical patients
- optic nerve sheath ultrasound
- intracranial hypertension
- bedside point-of-care ultrasound

\section{Resumo \\ Palavras-chave \\ - ultrassom point-of-care \\ - ultrassom na sala de emergência \\ - ultrassom em pacientes neurocríticos \\ - ultrassom do diâmetro da bainha do nervo óptico \\ - hipertensão intracraniana \\ - ultrassonografia point of-care à beira do leito}

Point-of-care ultrasound is modifying conducts in emergency care. The various medical specialties, in addition to traditional indications in cases of multiple trauma, are using this technique for rapid diagnosis at the bedside without patient mobilization and without radiation. Point-of-care ultrasound in neurocritical patients, through its transorbital window, can estimate the intracranial pressure by a non-invasive method. Through the measurement of the diameter of the optic nerve sheath $3 \mathrm{~mm}$ posterior to the retina, the intracranial pressure is estimated if the value of the diameter is $>5 \mathrm{~mm}$, as it has been verified in other studies. The present article describes the most current data on this topic, and it also highlights the need for more multicentric and randomized trials to determine the correct cut-off points that represent the high sensibility and specificity of the method.

A ultrassonografia point-of-care está modificando as condutas na sala de emergência. As diversas especialidades, além das indicações tradicionais ao politraumatizado, estão utilizando esta técnica para um rápido diagnóstico à beira do leito, sem a necessidade de mobilização do paciente e sem irradiação. Nos pacientes neurocríticos, a ultrassonografia point-of-care, através de sua janela transorbital, oferece uma técnica não invasiva para avaliação da pressão intracraniana. Por meio da medida do diâmetro da bainha do nervo óptico $3 \mathrm{~mm}$ posterior à retina, estima-se a pressão intracraniana se o valor desse diâmetro for superior a $5 \mathrm{~mm}$, conforme verificado em alguns estudos. Este artigo apresenta os dados mais atuais sobre o tema, destacando, ainda, a necessidade de mais estudos multicêntricos, randomizados, para a correta determinação dos valores de corte que representem a alta sensibilidade e especificidade do método. received

July 28, 2016

accepted

August 30, 2016
DOI https://doi.org/

10.1055/s-0036-1594301. ISSN 0103-5355.
Copyright (e 2019 by Thieme Revinter

Publicações Ltda, Rio de Janeiro, Brazil
License terms

(c) (1) $\ominus$ (5) 


\section{Introduction}

For more than 50 years, ultrasound has been a safe and efficient method to make clinical diagnoses. Currently, the equipment has become smaller, more precise, cheaper, with immediate results, and without causing any trauma to the patient. Its use has spread to practically every great reference center. It has been included in the syllabus of medicine schools, and it has been considered "the stethoscope of the future." Point-of-care ultrasound is currently being used in emergency rooms in almost every medical specialty. Images are obtained ate the bedside instantly, and can be reproduced as many times as necessary, in real time, and recorded for posterior assessment, if needed. ${ }^{1}$

The concept for point-of-care ultrasound has been developed for non-radiology physicians who wish to use another diagnostic tool at the bedside, in a non-invasive, safe, and fast way. Up to date, the most prominent uses of this tool included: guided vascular access in emergency rooms and intensive care, thoracenteses, paracenteses, as well as for the assessment of the free liquid in cases of polytrauma, with the focused abdominal sonography for trauma (FAST), having been replaced for the extended focused assessment sonography for trauma (E-FAST), which includes a broader view, considering pulmonary and cardiac assessments, apart from the windows already adjusted on the FAST. In this new concept, lesions of the lungs, including hemothorax and pneumothorax, as well as aortic and cardiac lesions, can also be diagnosed. More recently, however, some questions that are common in emergency settings can be answered with point-of-care ultrasound, such as: what is the patient's volemic state? Should we use inotropic or vasoactive drugs? Does the respiratory insufficiency have pulmonary or cardiac origins? Is there indication for decompressive craniectomy? Is there any midline shift $?^{2-4}$

\section{Objectives}

The goal of the present article is to describe the current knowledge on the use of point-of-care ultrasound to assess intracranial pressure measuring the diameter of optic nerve sheath through the transorbital window in critical patients.

\section{Materials and Methods}

The present is a descriptive and quantitative research that was performed through a literature narrative review on the Latin American and Caribbean Literature in Health Sciences (LILACS, in Portuguese) and the National Library of Medicine (PubMed) databases in July 2016, using the following descriptors: point-of-care ultrasound; ultrasound in emergency room; ultrasound in neurocritical care; intracranial hypertension; optic nerve sheath; and optic nerve ultrasound. The descriptors were combined for the search as follows: point-of-care ultrasound and optic nerve sheath; point-of-care ultrasound and neurocritical care; point-of-care ultrasound and emergency room; and point-of-care ultrasound and intracranial hypertension.
The study has as a guide the following question: can pointof-care ultrasound be used to assess intracranial pressure in a neurocritical patient?

The inclusion criteria were: updated publications mostly from 2001 to 2016, with rare exceptions, written in Portuguese, Spanish and English, with online access to the full text. Duplicate articles were excluded.

For the analysis of the articles included in this review, the following aspects were observed: the year of publication; the type of periodical; the place where the study was conducted; the methodology used; and the main results.

\section{Development}

Intracranial hypertension (IH) in the emergency setting. Intracranial hypertension ( $\mathrm{IH})$ is a frequent problem in emergency rooms and intensive care facilities, and in the case of an intracranial lesion, the recommendation is to maintain the pressure below $20-25 \mathrm{mmHg}$. The techniques currently available for this monitoring are invasive, with the introduction of an intraparenchymal and/or intraventricular catheter, with risk of hemorrhage and/or associated infections. Aa alternatives to the gold standard measurement, the invasive technique, there are options such as computed tomography (CT) of the brain or magnetic resonance imaging (MRI) of the encephalon, which will reveal indirect signs of IH with deletion of the cisterns of the base, deletion of the cortical grooves, loss of the interface between the white and gray matters, and midline deviation, but the accuracy of these imaging techniques is still uncertain. In this context, point-of-care ultrasound is shown to be a fast, reliable, safe and inexpensive method, which can be performed at the bedside. The sheath around the optic nerve is a continuation of the dura mater, reflecting the subarachnoid environment. The increase in intracranial pressure is immediately transmitted to the interior of the sheath that covers the optic nerve, promoting its distension, and, subsequently, papilledema. However, papilledema is a late event, which can take from hours to days to manifest, unlike its acute character, which can take seconds until the thickening of the optic nerve sheath. Point-of-care ultrasound can identify this distension in the optic nerve sheath starting from a prefixed distance from the retina, and it is an extremely useful tool in cases of cranioencephalic trauma, intracranial hemorrhages, and other brain lesions. ${ }^{5}$

Optical nerve anatomy. The optic canal, which is located on the lower wing of the sphenoid bone, receives the optic nerve (pair II of the cranial nerve) from the intraorbital region, bringing retinal afferences. This nerve is wrapped by a meningeal sheath consisting of the dura mater (pachymeninges), the arachnoid and the pia mater (both leptomeninges). Thus, the liquor content is also present in the subarachnoid space, reflecting its intracerebral pressure. The thickness of the optic nerve sheath directly translates the pressure of this liquor into the subarachnoid space, correlating directly to the measurement of the intracranial pressure. ${ }^{4}$ The closer to the eyeball, the greater the meningeal distensibility found, and this establishes a dilation visualized through the ultrasound as having a bulbous aspect. While papilledema may take a period ranging 
from days to weeks to appear, the distension of this bulbar region of the optic nerve sheath can be visualized almost instantaneously, in seconds, after the elevation of the intracranial pressure., 6 The first ultrasonographic description of the eyeball was performed in 1956 to estimate intracranial pressure in cadavers. However, the low quality of the equipment and the lack of methodology made its interpretation quite difficult. Only in 1996, with more sensitive equipment, it was possible to identify the dilation of the optic nerve sheath and its appropriate point of observation, at $3 \mathrm{~mm}$ posterior to the retina: this is the point most sensitive to ultrasound with the use of linear transducers. ${ }^{4,7}$

Ultrasonographic appearance of the optic nerve. At the transorbital ultrasound, the eyeball is visualized as round, darken (black) and full of fluid. The anterior chamber is anechoic and corresponds to the lens, while the iris is observed as bright or echogenic. The choroid and the retina are visualized as a thin greyish layer on the posterior face of the eyeball. The optic nerve reveals itself as a black band running out of the eyeball, in the posterior direction, and it is necessary to position it in the center of the ultrasound screen. The optic nerve sheath is visualized through the ultrasound with higher reflectivity, that is, it will be clearer compared with the nerve itself. Some authors describe the signs of dilation of the optic nerve bulb, $3 \mathrm{~mm}$ from the retina, as a sign of the crescent, indicating the presence of $\mathrm{IH}^{8,9}$

Technique recommended to estimate intracranial pressure. Although there still is no universal consensus, some general principles should be observed for optimization and to be able to draw comparisons between professionals. The transducer used should be of linear high frequency (7$10 \mathrm{MHz}$ ), preferably with a good quality resolution equipment and viewing capacity of structures at depths of $5-6 \mathrm{~cm}$. The examiner should apply gel on the closed eyelids, supporting his hand with the transducer on a rigid bone structure, to avoid pressure on the eyeball. Initially, the transducer will be placed in the transverse position, and will be slowly shifted to the parasagittal position; the optic nerve should be centered on the ultrasound screen, with concomitant visualization of the lens and iris; Both eyes should be evaluated in this exam. Once properly positioned, the image is frozen, and the transducer is removed from the eyelid; the examiner locates the spot $3 \mathrm{~mm}$ from the retina and assesses the diameter of the sheath of the optic nerve (-Fig. 1). The authors usually recommend that this measurement be made at least 2 or 3 times for greater reliability of the results. It is also important to emphasize that there is no greater precision in measurement made with the transducer positioned parasagittally (longitudinally) or transversally. The patient's head can be in horizontal ventral decubitus, or even in decubitus elevated at $20-30^{\circ} .2,5,7,10$

Reference values of the optic nerve sheath diameter and its correlation with intracranial pressure. The value of the diameter of the sheath of the optic nerve that can reflect intracranial hypertension is subject to debate, and has not yet been clearly defined in the literature. Based on the maximum normal value for intracranial pressure of $15 \mathrm{mmHg}$, with IH defined when this value is $\geq 20 \mathrm{mmHg}$, several authors believe that $5 \mathrm{~mm}$ of thickness for the sheath is a reasonable limit. However, many studies (with small samples) don't agree with this value: Rajajee et $\mathrm{al}^{5}$ use

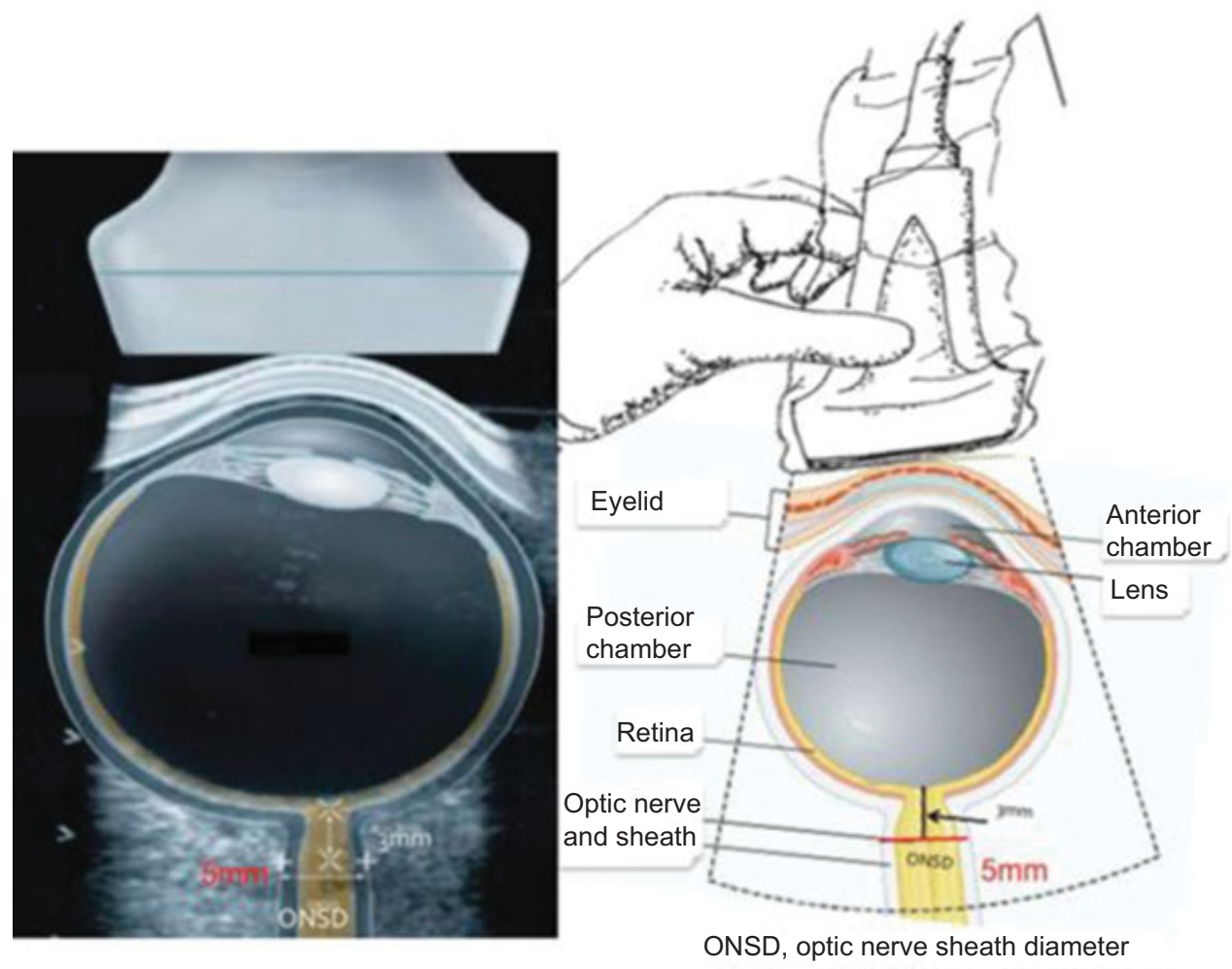

Fig. 1 Recommended technique to measure the diameter of the optic nerve sheath and anatomical structures of the eye and the nerve correlated with the ultrasound image. 
Table 1 Studies that propose a cut-off point for the optic nerve sheath diameter that would best correspond to intracranial pressure $>20 \mathrm{mmHg}$, with their respective sensitivity and specificity

\begin{tabular}{|l|l|l|l|l|}
\hline Study & Optic nerve sheath diameter & Patients (n) & Sensitivity & Specificity \\
\hline Blaivas et al & 10 & 35 & $100 \%$ & $95 \%$ \\
\hline Goel et al & $5.0 \mathrm{~mm}$ & 100 & $98.6 \%$ & $92.8 \%$ \\
\hline Tayal et al $^{18}$ & $5.0 \mathrm{~mm}$ & 59 & $100 \%$ & $63 \%$ \\
\hline Kimberly et al $^{17}$ & $5.0 \mathrm{~mm}$ & 15 & $88 \%$ & $93 \%$ \\
\hline Moretti et al & $5.0 \mathrm{~mm}$ & 63 & $94 \%$ & $76 \%$ \\
\hline Geeraerts et al $^{14}$ & $5.2 \mathrm{~mm}$ & 37 & $90 \%$ & $84 \%$ \\
\hline Soldatos et al & $5.9 \mathrm{~mm}$ & 76 & $74.1 \%$ & $100 \%$ \\
\hline Shirodkar et al & $5.9 \mathrm{~mm}$ & 101 & $75 \%$ & $100 \%$ \\
\hline Wang et al & $22 * *$ & 279 & $95 \%$ & $92 \%$ \\
\hline
\end{tabular}

Notes: Source: Adapted from Shevlin ${ }^{7}$ and Ochoa-Pérez and Cardozo-Ocampo. ${ }^{2 *}$ Indian population. ${ }^{* *}$ Chinese population.

$5.2 \mathrm{~mm}$; Soldatos et al, ${ }^{4} 5.7 \mathrm{~mm}$; and Bäuerle and Nedelmann, ${ }^{11} 5.8 \mathrm{~mm}$. Shevlin ${ }^{7}$ observed that the variation in the limit in the several studies to this moment is between $4.8 \mathrm{~mm}$ and $6.0 \mathrm{~mm}$, which is a complicating factor to define IH. Several studies that proposed these different reference values cannot be compared, since they use different methodologies and were performed on different populations, making new prospective and multicentric studies directed to this end necessary. (- Table 1).$^{5,11-16}$

Confirmation of IH through different ultrasound methods. The measurement of intracranial pressure by intraventricular catheterization is considered the gold standard method in the evaluation of IH. However, the risk of infection and hemorrhage is inherent to the procedure, as well as to the clinical status of the patient. The correlation between the increase in the diameter of the optic nerve sheath and the intracranial pressure measured by intraventricular catheter has not been well established, due to the aggressiveness of the procedure and the clinical condition of the patients. Rajajee et $\mathrm{al}^{5}$ assessed 536 patients with intraventricular catheter and correlated the data with the diameter of the sheath of the optic nerve, finding a strong correlation between $\mathrm{IH}>20 \mathrm{mmHg}$ and a mean sheath diameter of $5.3 \mathrm{~mm}$ (5.1-5.7 mm), while intracranial pressure $<20 \mathrm{mmHg}$ correlated to the mean of $4 \mathrm{~mm}$ in diameter of the optic nerve sheath $(p<0.0001)$. It is important to highlight that the authors did not find a statistically significant difference between patients submitted to mechanical pulmonary ventilation and those who did not intubate. ${ }^{5}$ Neuroimaging criteria to confirm increased optic nerve sheath thickness ( $>5 \mathrm{~mm}$ ) findings were used and correlated with midline shifts ( $>3 \mathrm{~mm}$ ), ventricle III deletion, mass effect, hydrocephaly, and signs of early or late cerebral edema, and significant results, with $100 \%$ of sensitivity and 95\% of specificity, were found when the cranial CT was used. $^{5,10}$ Ochoa-Pérez and Cardozo-Ocampo ${ }^{2}$ emphasize that, in addition to the measurement of the optic nerve sheath diameter to estimate $\mathrm{IH}$, a bone window performed through the temporal bone scale with a low frequency transducer $(1-5 \mathrm{MHz})$ is able to detect the midline shift. The technique is essentially the same used in transcranial color Doppler, except for the fact that the structures are visualized in ultrasound B (brightness) mode. The compressions of the lateral ventricles and midline shifts resulting from ischemic vascular accidents, sub- and extradural hematomas, as well as hemorrhages from the basal nuclei, may be visualized. Shunts can be placed with the help of this technique. However, due to the interference of the bone, the authors report that, in $~ 15 \%$ of the cases, the images of the cerebral parenchyma are not satisfactory. In those undergoing decompressive craniectomies, the use of point-of-care ultrasound becomes an even more useful tool, with the area of absence of bone as the most appropriate window. ${ }^{2,9}$

Arguments in favor of and contrary to the use of the optic nerve sheath diameter for the evaluation of intracranial pressure. The advantages of using ultrasound at the bedside are: reproducibility, non-invasiveness, low cost, portability, rapid execution, absence of ionizing radiation, and possibility of performance without transfer of the patient out of the emergency room or intensive care unit. Among the factors considered to be disadvantageous, one can mention: lack of preparation of intensivist and emergency physicians in the use of point-of-care ultrasound at the bedside, which is a new technique; the need for a learning curve, since ultrasound is a technique dependent on the operator's ability; lack of reference values based on large prospective and multicenter population studies; relative risk of ocular globe injury due to excess pressure of the transducer on the patient's eyelid; risk of thermal injury by the absorption of the apparatus energy and heat transformation; and inability to use it in cases of suspicion of lesions of the eyeball., ${ }^{4}$

\section{Conclusion}

Point-of-care ultrasound is a reality in large, high complexity centers around the world. Its characteristics contribute to its dissemination: it is a low-cost exam, with good accuracy, fast, non-invasive, recommended for the non-specialist physician, with no ionizing radiation, and it can be performed at the bedside. Several medical specialties have been using point-of-care ultrasound, and neurology and neurosurgery 
are no exception. The idea of estimating intracranial pressure using at the bedside a tool that is non-invasive and fast has been gaining space in emergency medicine. The transorbital window enables the visualization of the optic nerve sheath bilaterally, enabling the estimation of the intracranial pressure transmitted by the liquor to this structure. Its diameter measured $3 \mathrm{~mm}$ posterior to the retina seems to represent an intracranial pressure within the limits of normality when lower than $5 \mathrm{~mm}$. However, there are still no large prospective and multicenter studies that validate these values. It is also not known for certain whether all intracranial injuries, in victims of polytrauma, may have the same reference value. Another possibility is through the transtemporal window, in which midline shifts, the size of the lateral ventricles, and the presence of hematomas can be observed. Despite the need for further studies to validate the reference values, point-ofcare ultrasound in neurology is an extremely promising tool for neurocritical patients.

Conflicts of Interest

The authors have none to declare.

\section{References}

1 Moore CL, Copel JA. Point-of-care ultrasonography. N Engl J Med 2011;364(08):749-757

2 Ochoa-Pérez L, Cardozo-Ocampo A. Ultrasound applications in the central nervous system for neuroanaesthesia and neurocritical care. Rev Colomb Anestesiol 2015;43(04):314-320

3 Mehrpour M, Oliaee Torshizi F, Esmaeeli S, Taghipour S, Abdollahi S. Optic nerve sonography in the diagnostic evaluation of pseudopapilledema and raised intracranial pressure: a cross-sectional study. Neurol Res Int 2015;2015:146059

4 Soldatos T, Chatzimichail K, Papathanasiou M, Gouliamos A. Optic nerve sonography: a new window for the non-invasive evaluation of intracranial pressure in brain injury. Emerg Med J 2009;26(09): 630-634

5 Rajajee V, Vanaman M, Fletcher JJ, Jacobs TL. Optic nerve ultrasound for the detection of raised intracranial pressure. Neurocrit Care 2011;15(03):506-515

6 Hansen HÇ, Helmke K. Validation of the optic nerve sheath response to changing cerebrospinal fluid pressure: ultrasound findings during intrathecal infusion tests. J Neurosurg 1997;87(01):34-40

7 Shevlin C. Optic nerve sheath ultrasound for the bedside diagnosis of intracranial hypertension: pitfalls and potential. Critical Care Horizons 2015;1:22-30

8 Marchese RF, Mistry RD, Scarfone RJ, Chen AE. Identification of optic disc elevation and the crescent sign using point-of-care ocular ultrasound in children. Pediatr Emerg Care 2015;31(04): 304-307

9 Lochner P, Cantello R, Brigo F, et al. Transorbital sonography in acute optic neuritis: a case-control study. AJNR Am J Neuroradiol 2014;35(12):2371-2375

10 Blaivas M, Theodoro D, Sierzenski PR. Elevated intracranial pressure detected by bedside emergency ultrasonography of the optic nerve sheath. Acad Emerg Med 2003;10(04):376-381

11 Bäuerle J, Nedelmann M. Sonographic assessment of the optic nerve sheath in idiopathic intracranial hypertension. J Neurol 2011;258(11):2014-2019

12 Soldatos T, Karakitsos D, Chatzimichail K, Papathanasiou M, Gouliamos A, Karabinis A. Optic nerve sonography in the diagnostic evaluation of adult brain injury. Crit Care 2008;12(03):R67

13 Geeraerts T, Launey Y, Martin L, et al. Ultrasonography of the optic nerve sheath may be useful for detecting raised intracranial pressure after severe brain injury. Intensive Care Med 2007;33 (10):1704-1711

14 Geeraerts T, Merceron S, Benhamou D, Vigué B, Duranteau J. Noninvasive assessment of intracranial pressure using ocular sonography in neurocritical care patients. Intensive Care Med 2008;34 (11):2062-2067

15 Strumwasser A, Kwan RO, Yeung L, et al. Sonographic optic nerve sheath diameter as an estimate of intracranial pressure in adult trauma. J Surg Res 2011;170(02):265-271

16 Lochner P, Brio F, Zedde ML, et al. Feasibility and usefulness of ultrasonography in idiopathic intracranial hypertension or secondary intracranial hypertension. BMC Neurol 2016;16:85-97

17 Goel RS, Goyal NK, Dharap SB, Kumar M, Gore MA. Utility of optic nerve ultrasonography in head injury. Injury 2008;39(05): 519-524

18 Tayal VS, Neulander M, Norton HJ, Foster T, Saunders T, Blaivas M. Emergency department sonographic measurement of optic nerve sheath diameter to detect findings of increased intracranial pressure in adult head injury patients. Ann Emerg Med 2007; 49(04):508-514

19 Kimberly HH, Shah S, Marill K, Noble V. Correlation of optic nerve sheath diameter with direct measurement of intracranial pressure. Acad Emerg Med 2008;15(02):201-204

20 Moretti R, Pizzi B, Cassini F, Vivaldi N. Reliability of optic nerve ultrasound for the evaluation of patients with spontaneous intracranial hemorrhage. Neurocrit Care 2009;11(03):406-410

21 Shirodkar CG, Rao SM, Mutkule DP, Harde YR, Venkategowda PM, Mahesh MU. Optic nerve sheath diameter as a marker for evaluation and prognostication of intracranial pressure in Indian patients: An observational study. Indian J Crit Care Med 2014; 18(11):728-734

22 Wang L, Feng L, Yao Y, et al. Optimal optic nerve sheath diameter threshold for the identification of elevated opening pressure on lumbar puncture in a Chinese population. PLoS One 2015; 10(02): e0117939 